\title{
Towards Smart Planning Conservation of Heritage Cities: Digital Technologies and Heritage Conservation Planning
}

\author{
Claudia Trillo ${ }^{1[0000-0002-5961-0706]}$, Rania Aburamadan ${ }^{2}$, Busisiwe Chikomborero Ncube \\ Makore ${ }^{1[0000-0001-8943-2093]}$, Chika Udeaja ${ }^{3[0000-0002-6405-9664]}$, Athena Moustaka ${ }^{1 \text { [0000-0002- }}$ \\ 3039-7315], Kwasi Gyau Baffour Awuah [10000-0001-7927-7528], Dilip A. Patel ${ }^{4[0000-0002-6874-8141]}$, \\ Lukman E. Mansuri4[0000-0003-4823-8053] \\ ${ }^{1}$ School of Science, Engineering and the Environment, University of Salford, UK \\ ${ }^{2}$ School of Architecture, University of Philadelphia, Jordan \\ ${ }^{3}$ London South Bank University, UK \\ ${ }^{4}$ Sardar Vallabhbahi National Institute of Technology, Surat 395007, India \\ lncsespringer.com
}

\begin{abstract}
Consensus exists on the importance of local identity and diversity in the sustainability discourse, including community resilience. As result, cultural policies are essential to enable sustainability goals. In the construction industry, digital technologies are playing a significant role in flattening the richness and distinctiveness of local contexts and homogenizing languages and practices, under the pressure of the constant urge to reduce costs and the necessity to comply with a sometime overwhelming plethora of technical and legal requirements and standards. The ambition of this paper is to shed light to the interplay between digital technologies, planning practice and tangible heritage conservation in the city, by clarifying the dynamic among the three fields and their implications in the practice. In so doing, this paper aims at offering recommendations that can inform the smart heritage conservation planning practice worldwide, and can be used by experts working for heritage conservation authorities, local authorities, professional practices, charities and digital technologies companies.
\end{abstract}

Keywords: Smart heritage, Smart cities, heritage conservation, planning, digital technologies, India, Jordan.

\section{Introduction}

Interest in applying digital technologies in the two domains of urban planning and heritage conservation is growing, both in the scholarship, and in the applied practice. The application of digital technologies to the planning area relies on a widespread body of knowledge, included within the broader domain of "smart cities". Scholarship on smart cities unveiled benefits and threats deriving from the massive use of digital technologies on people's lives, by exploring the variety of issues and opportunities that big data, platforms and IT tools can offer. Examples of IT tools includes the uses of Geographic Information systems (GIS), Global Positioning System (GPS). Digital camera, laser 
scanners, virtual and augmented reality, Building Information Modelling (BIM) (Trillo et al., 2020; Udeaja et al., 2019), Artificial Intelligence (Mansuri et. al. 2019, Mansuri and Patel 2021). The various Communities Of Practices and stakeholders around the world, including chartered associations and global institutions such as the Royal Town of Planning Institution (RTPI) in the UK (RTPI, 2021), American Planning Association (APA) in the United States (Barth, 2019), the European Commission in the European member states (European Commission, 2021), nowadays converge on the belief that digital technologies are so pervasive, that they need to be operationalized within all levels of management and systems, thus setting the context for a new disciplinary approach to the planning practice, which requires critical understanding of the implications of such a massive use of digital technologies on issues such as democracy, diversity, cultural meanings.

For what concerns the impact of digital technologies on conservation of tangible heritage, the wider discourse that incorporates this domain is usually the application of digital technologies on the construction industry. This spans from the pervasive influence of digital design on architectural and engineering practice, to the use of digital instruments and tools, including digital platforms for data sharing and collaboration. Other examples include Building Information Modelling (BIM) objects, digital archives for materials and technical details, instruments and tools for digitalization of the different step of traditionally hand-made surveys, such as laser scanning, digital photogrammetry. The advantages offered by digital technologies to tangible heritage conservation often emphasize time and money saving in surveying and opportunities for storing and exchanging large amount of data, whilst detrimental impacts of such a use are associated with impoverishment and banalization of complex and articulated assets.

The interplay between the three domains, i.e. digital technologies, planning practice and heritage conservation, is still largely uncovered by both the international scholarship and international practice, one possible reason being the difficulty of cross-analysis three areas of increasing complexity and encompassing very different conceptual backgrounds, from cultural matters, identity, diversity, history (the domain of tangible heritage) to socio- political, legal and technical matters (the domain of planning) and technical, philosophical, ethical matters (the domain of digital technologies).

The ambition of this paper is to shed light to the interplay between digital technologies, planning practice and tangible heritage conservation, by clarifying the dynamic among the three fields and their implications in the practice. In so doing, this paper aims at offering recommendations that can inform the heritage conservation planning practice at a global level, and can be used by experts working for heritage conservation authorities, local authorities, local planning officials, professional practices, charities and digital technologies companies.

\section{Smart Heritage in Urban Planning: a literature review}

The discussion in this section covers the themes emerging from a literature review on smart heritage in urban planning. Keyword searches were used including "smart herit- 
age" as the main term and secondary terms such as, "planning", "heritage conservation". Papers found in the keyword searches were checked manually against the selection criteria. Therefore, this section includes the conceptualization of smart heritage in urban planning (section 2.1), the identified smart technologies for sustainable urban heritage management (section 2.2) and the challenges emerged from the data analytics for the processes and practices of smart heritage planning (section 2.3). Finally, the literature review has been complemented with more investigation in existing reports and guidelines, allowing to identify gaps and justify the necessity of this study in section 2.4.

\subsection{Conceptualizing smart heritage for urban heritage conservation planning and management}

The concept of the "smart city" has evolved in recent years shifting towards an intelligent infrastructure that harnesses the capabilities of technology to create an interactive dialogue between the citizens of a city and the city. New technologies (smart infrastructure) merges with the social capital of a city (users, innovation, learning, knowledge) to construct a smart and effective urban system that connects, protects and enhances the lives of a city's citizens. This dynamic interaction has been recognized as leading to a more efficient use of a city's resources and consequently, becoming an ideological vision for self-promotion. The new practices and services merging from smart cities have significant impacts on policy making and urban planning. More recently urban planning has increased engagement with the "smart cities" discourse and agendas of smart cities as a means to better understand the heightened role of technology in the management of collective urban services (Coletta, Evans, Heaphy, \& Kitchin, 2019; Karvonen, Cugurullo, \& Caprotti, 2019). The conceptualization of the term "smart" in the context of heritage and planning showed relative variety in the selected literature. Traditional discourses have often viewed the matters of heritage conservation and planning and issues of sustainability and smart cities as antagonistic. Smart city agendas have traditionally been understood as promoting universal standardization and thereby reducing the nuances of the mode of planning. However, the selected literature suggests a clear shift from this discourse and towards a complementary relationship in creating smart heritage cities in a manner that respects cultural heritage and carefully endeavours to embed the diversity of data related to heritage (Dornelles et al., 2020). The new technologies applied to contemporary urban development create an interconnected information system through processes, measuring instruments, simulators, equipment, software systems and hardware. In this context the open, sustainable city can be created through real-time analysis of urban life and innovative modes of urban management (Kitchin, 2014). In some cases, smart heritage cities remain at this "branding" and associative level often combining with terms such as "sustainable cities" and "inclusive cities" with no clear articulation of the use of smart technologies and how they are embedded into the planning system (Ji \& Shao, 2017; Badawi, 2017). Liu (2018) acknowledges that themes such as cultural, touristic, creativity and innovation driven development, accessibility to services and quality of life are horizontally present throughout smart city strategies in China. However, cultural heritage promotion as an objective is not explicit 
in any of them. Although the evidence of publications from India in the search were low, it is clear that there is a continuing discourse in urban planning relevant to the implementation of smart heritage cities. In India, incredible investment has been made into the creation of smart cities. Cities are continuously identified for inclusion in smart city programs, often due to tourist and economic potential such as Jaipur. In this regard, the heritage preservation of the city is embedded within the programs for creating smart cities (Jawaid et al., 2017). Specific aspects of the program such as master-planning are endorsed by the regional and local authorities and used for heritage and resource management and environment (Ghadei 2018).

A frequent conceptualization is the integration of historic preservation, heritage development, and tourism in local and regional smart cities and growth strategies and policies to stimulate the state and local economies (Facca \& Aldrich, 2011, Mar et al., 2018). The formulation of regional innovation policies and strategies currently implemented in regions of the European Union (2014-2020), assume an entrepreneurial approach to innovation, where local institutions play a central role through a smart specialization approach (Mc Cann, \& Ortega-Argiles, 2011). This approach also stresses the crucial role of "enabling technologies" which is explained in the next section for the purposes of information and communication technologies as core strategic elements in the planning process and practice.

\subsection{Smart enabling technologies for sustainable urban heritage management}

In the context of smart cultural heritage, the "smartness" requirements of each are equally aligned to emerging intelligent and contextualized services. Across the literature, these services are generally made possible by a common set of key technologies that are becoming ubiquitous and inseparably identified with the realization of smart developments (Borda \& Bowen, 2017). Diverse smart technologies were suggested from the selected literature to effectively preserve and manage cultural heritage. Dutra et al., (2020) and Borda and Bowen (2017) conducted a literature search on smart tools used in heritage planning and identified that 3D scanning techniques, Building Information Modelling (BIM), mobile applications for integrated management of asset preservation and the sensors for acquisition and analysis of data from the collections in real time were some of the smart technologies used for planning the preservation of cultural heritage in the context of the smart cities. Other deployment of technologies includes the use of Internet of Things (IoT) technology for the digitalization of a database or museum information system (MIS) typically used as an electronic archive or catalog for cultural heritage (Korzun et al., 2017). Koukopoulos \& Koukopoulos (2018) proposes an intelligent system in South Korea designed using a combination of technologies from dedicated mobile applications to analyze collected data in real-time for the effective management of urban cultural heritage events such as carnivals. The potential of gathering real time data from smart mobiles for spatial mapping and tracking in urban planning was also suggested by Toha \& Ismail (2015). Sun et al., (2016) and Navarro de Pablos et al., (2018) argue that IoT and big data analytics has the potential to provide a ubiquitous network of connected devices and smart sensors for smart heritage and enhance the services in the area of tourism and cultural heritage. In the study 
by Sun et al., (2016) on an Italian town, Sun et al., (2016) identify two opportunities of IoT in smart heritage cities: (1) mobile crowdsensing, (2) cyber-physical cloud computing. Mobile crowdsensing relies on data collected from mobile sensing devices. Cyberphysical cloud computing systems are smart networked systems with embedded sensors, processors and actuators that are designed to sense and interact with the physical world. Emerging technologies that provide a visualization to aid decision making such as augmented reality (AR), virtual reality (VR), and mixed reality (MR), are also recommended as valuable for urban regeneration project management (Pica et al., 2019).

Building Information Modelling (BIM) is described as a valuable tool for the effective communication and management of heritage information and within the area of urban planning. Characteristically, BIM uses three-dimensional building modelling software with smart parametric object features, combining tangible and intangible data to increase efficiency in building design and construction (Udeaja et al., 2020). The advantages of using BIM offer a platform with heterogeneous information that is available multiple stakeholders to enable better decision making at a local level. Geographic Information Systems (GIS) are mentioned as widely accepted and accessible for urban planners. Planners have adapted the GIS tools to meet their particular requirements for the purpose of decision making and often integrated existing analytical techniques with GIS packages to develop user friendly planning tools (Sabri et al., 2014). A possible limitation is the use of GIS with other technologies and software to provide a holistic data for strategic and local heritage conservation planning. Integrating GIS is described through the Historical Small Smart City Protocol, dataset framework based on GIS (geographic information system) software proposed by Pica et al., (2019). The framework is primarily implemented using open big data and local data. Its purpose is to assess future scenarios for developing integrated strategic planning that is oriented toward sustainable management, in order to develop and preserve minor historical centers.

\subsection{Data analytics for smart heritage}

The literature search revealed significant opportunities for the use of smart data in urban heritage planning. The smart physical and computational processes will enable the accumulation of large amounts of data, which can be analyzed, interpreted, and appropriately leveraged to facilitate reasonably accurate decision-making and control in urban heritage planning and management (Sun et al., 2017). Several challenges with data analytics in the creation of smart heritage cities are identified in the literature include: Data standards and interoperability, Data architecture, Data heterogeneity, Data administration and management, Organizational capacity and lack of skills and awareness of smart technologies.

Inconsistency in the production and conceptualization of data and different standardizations reduces interoperability of data and tools (Petti, Trillo \& Makore, 2020, Mar et al., 2018). The incorporation of such standards aide in the creation of a generic system for heritage planning and management in diverse contexts and promote sharing and longevity of data regardless of inevitable technological advances. Sabri et al., (2014) suggests that monolithic systems are replaced by smart components designed to interoperate through compliance with industry-wide standards. Therefore, the existing 
challenge in many national contexts is how to improve intelligent data interpretation and semantic interoperability? Without a clear standardization, decision making is very uncertain. Interoperability and standardization of data platforms improves decision making under uncertainty by understanding assessment, representation and propagation of uncertainty, developing robust-optimization methods, and designing optimal sequential decision making (Sun et al., 2017). To enhance the comparability of heritage data across cities and countries, there is a crucial requirement for standardized methods for perceiving, valuing, measuring and monitoring heritage. Therefore, national and local capacity development is needed to ensure the sustainability of national and local processes. The harmonization of these processes using similar standards and conceptualization can allow for the comparison of data among countries toward the achievement of the Sustainable Development Goals.

A robust data architecture is crucial to successful implementation of smart technologies. Riganti (2017) proposes a smart heritage intelligent environment with an architecture dedicated to deliver elements such as crowdsourcing, e-governance, valuation and case-based reasoning. Open Data platforms with static data sources are useful. In this regard an example is the OpenData Trentino which combines data concerning tourist attractions/services, photos, videos, 3D content and special location data of specific businesses (Sun et al., 2017). Dynamic real-time data will often use the capabilities of real-time data sources and stations and more recently the use of crowdsourcing. Open geo data published freely online by municipal, regional, and national authorities is used to develop smart heritage frameworks (Pica et al., 2019; Pili, 2018; Scorza et al., 2019).

The data relevant to urban heritage planning and management is typically heterogeneous and diverse. Smart data on a heritage building may including the tangible qualities such as building structure and materials and the state of the building components such as doors and windows. In addition to this data is the intangible qualities of the building such as occupancy, history, cultural values. The challenge therefore is how to unify data representation and processing models to accommodate heterogeneous or new types of data. The use of information management platforms such as HBIM are suggested in literature as playing a significant role in harmonising heterogeneous data in one system (Trillo et al., 2020; Udeaja et al., 2020).

Furthermore, the trends towards smart heritage management have influenced a shift in data administration and management. The roles of national government, state/local government and private sector are changing to accommodate how data is shared and managed and therefore localizing decision making (Sabri et al., 2014). The shifts are largely seen in developed countries that have upskilled and developed structures that support the integration of technologies. Smart heritage systems could significantly facilitate the management of public affairs by local administrations moving gradually towards widespread data distribution to the general public (citizens, professionals, public, and/or private bodies) (Pica et al., 2019).

However, in many countries, there exists a definite gap in skills, capacity and awareness of the integrating of new technologies in planning strategies and implementations. This suggests a resistance to shifting of traditional structures and ways of working that may limit the success of smart technologies and processes. Navarro de Pablos et al., 
(2018) describe the consequences of technological enclosures that may cause disconnection and fragility within a city infrastructure. In the example of Valdenebro \& Gimena (2018), urban planners hesitated to engage with the proposed smart technologies due to the complexity of heritage such as in the case study of the city of Pamplona, Spain. Valdenebro \& Gimena (2018) describe that there was knowledge of some previous experiences of technology executed in new urban developments but not in constrained spaces as the case of a medieval historic centre.

\subsection{The interplay between digital technologies, planning practice and heritage conservation}

The literature search revealed significant opportunities for the use of digital technologies in both the domain of planning (smart cities) and heritage (smart heritage), however, it also revealed paucity of reflection on the interconnections between smart cities and smart heritage, which is reflected in gaps at policy level. As an example, the European continent has been a pioneer in the acknowledgement of the necessity to cooperate towards digitalization of cultural heritage (2019 Declaration of Cooperation on advancing the digitization of cultural heritage) (Petti, Trillo \& Makore, 2019). In support of the principles expressed by this declaration, the Expert Group on Digital Cultural Heritage and Europeana has issued a document explaining the "Basic principles and tips for $3 \mathrm{D}$ digitisation of tangible cultural heritage for cultural heritage professionals and institutions and other custodians of cultural heritage" (European Commission, 2021). This document covers issues that are quite common in data management (costs, quality, storage, ownership), and offers valuable insights and guidance, but does not articulate the discussion with respect to the different strategies that enable heritage conservation and most importantly, does not differentiate among isolated heritage episodes and complex heritage environments.

Indeed, the concept that not only the individual tangible heritage objects deserve attention, but also their articulation through the materiality of the urban fabric, has been capturing the attention of planning theory and practice gradually, and this has happened systematically at international level only in recent times. Italy has pioneered the conceptualization of the so called "historic centre", which became popular following the Gubbio Charter, back in 1960. This latter was signed by a group of politicians, local administrators, experts and academic, and paved the way to a rich set of planning policies and tools enabling an effective conservation of major and minor historic centres (ANCSA, 1960). One of the key- principles stated in the charter was based on the idea that conservation should be extended to the entirety of the physical urban fabric and therefore conservation policies should be pursued at neighborhood level, not at the level of the individual building. In fact, it was the neighbourhood and not the individual building that had to be identified for planning interventions, by including private and public assets, main and minor roads, exterior and interior of the buildings.

Moving forward, the ICOMOS Washington Charter (1987), by building on the UNESCO "Recommendation Concerning the Safeguarding and Contemporary Role of Historic Areas" (Warsaw - Nairobi, 1976). This was reinforced at international level the concept that the entirety of the urban fabric needed attention from conservation 
policies, and should be included in the wider socio-economic policies and urban and regional planning (ICOMOS, 1987). The Washington Charter was then revisited in 2011 by the $17^{\text {th }}$ ICOMOS General Assembly, with the document "The Valletta Principles for the Safeguarding and Management of Historic Cities, Towns and Urban Areas". This was done by incorporating the concept of sustainable development in the notion of heritage conservation, and by emphasizing the interconnected nature of tangible and intangible values underpinned in the materiality of the urban fabric, as such, considering heritage as part of the urban ecosystem. In the same year (2011), the $36^{\text {th }}$ session of the UNESCO's General Conference adopted the "Recommendation on the Historic Urban Landscape", popularizing internationally the acronym HUL (Historic Urban Landscape), as instrumental to vehicle the complexity of the societal, cultural and developmental values incorporated in the materiality of the urban shape.

The inextricability of the interconnection between heritage and urban shape challenges the idea that conservation policies can remain confined within the perspective of the individual building, and therefore digitalization of heritage for the purpose of heritage conservation requires re-casting it within the wider scope of planning for conservation, i.e., in the contemporary digital era, within the wider domain of smart cities. What mechanisms are the most appropriate to disentangle the complexity of this nexus and to make it manageable through the appropriate digital technologies? This is a question that as far as in our knowledge remains unresolved. It is the aim of this paper to push the body of knowledge forward, by drawing insights from two parallel research projects in India and in Jordan.

\section{$3 \quad$ Methodology}

The research study aims to shed light to the interplay between digital technologies, planning practice and tangible heritage conservation, by clarifying the dynamic among the three fields and their implications in the practice. The discussion offered in this paper is a body of knowledge accumulated in two research projects over a three years' time by a team of researchers located in three countries, United Kingdom, India and Jordan. Two case studies in Jordan and India have been conducted over the last three years on urban heritage conservation and digital technologies. The findings from these case studies have been analyzed and developed into a set of guidelines of general applicability. The guidelines suggested in this paper can inform the heritage conservation planning practice worldwide, and can be used by experts working for heritage conservation authorities, local authorities, professional practices, charities and digital technologies companies. The research methodology for both case studies consisted in producing 3D digital models of a range of different heritage assets, and by questioning the usability of the data produced through a discussion with local stakeholders. The two case studies are the two cities of Surat in Gujarat, India, and As Salt in Jordan (Figure 1). Both case studies have required extensive data collection, both in terms of data acquisition (heritage assets) and in terms of stakeholders' engagement. 
The qualitative set of data includes national laws on heritage conservation, local plans, regulations and guidelines on heritage conservation and planning, strategic documents on smart cities, any other document and report relevant to the topic. The team has engaged in numerous exploratory interviews with a wide range of experts, to make sure that the context was clear, by triangulating secondary data with primary data collected through non-structured interviews, with local city planners, architects and experts in the fields covered by this research, as broadly discussed in previous works (Udeaja et al 2020, Trillo et al 2020). Site visits to the heritage centres were conducted by the team, to accurately contextualize the $3 \mathrm{D}$ models. The data set for both cases included digital acquisition of 3D images of chosen buildings within the heritage centres, delivered through different technologies. Finally, both case studies were discussed through various real and virtual focus groups, involving a high number of local experts (in the order of 50 participants per case study).

The data set regarding the buildings has been built with different criteria in the two case studies. In the case of Surat, the team focused on the selection of a variety of monuments, with the aim to support promotion of heritage assets and raising awareness at local level on the importance of tangible and intangible heritage. The city of Surat is a mid-size Indian city in the Gujarat state, with a glorious past based on the diamonds industry and currently challenged by rapid urbanization, including the construction of a new metro line cross cutting the heritage core, and the demolition of private housing in the two historic areas of the city, i.e. Gopi Surat and Rander. Meetings with planning officials and local experts confirmed the challenges to local heritage and the potential of digital technologies, including a Surat Smart City programme led by the local authority. In this case study, digital technologies have been used to support the creation of a narrative, aimed at eliciting sense of proud and belonging in the community and hopefully contribute to the conservation of heritage through local regulations, focused on heritage monuments, e.g. the British Cemetery (Figure 1).

In the case of As-Salt, the team focused on private houses. The City of As Salt is a small-size town close to the capital city of Amman in Jordan, rich in architectural heritage due to its importance in the Ottoman period. The local government is keen to build on this unique feature to foster local economic development, and as part of this strategy, the City has applied to be inscribed within the UNESCO heritage list. In this case study, digital technologies have been used to explore the potential of 3D models as a vehicle to support a management plan for heritage conservation, following the tradition of the "Handbook for conservation" (Trillo et al, 2020). The concept that lies at the core of this planning instrument, which was developed through some pioneering cases in both large and small Italian cities in the late 1970s (Pesaro, Rome, Citta' di Castello), is the assumption that heritage centres are made of the interconnection of different scales: urban fabric / buildings / architectural components. The physical shape of heritage cities rests on the structured articulation of technological details, which are rooted in local materials and in skills often developed through generations. Handbooks for conservation included a range of exemplar buildings, disassembled by components with the purpose to support architects and designers in their work of designing interventions on similar buildings. In the case of As Salt, where the uniqueness of the HUL rests on the golden limestone magnificent Ottoman houses, choosing two Ottoman houses (e.g. 
Qaqeesh house, figure 1) was instrumental to create a library of digital components for heritage houses.

Because of the nature of the two research projects, aimed at tailoring the digitalization of the chosen heritage to the local context by co-deciding and co-producing the project operational strategy in collaboration with local stakeholders, the two cases are not suitable to be discussed in a comparative perspective. However, both cases present commonalities that are worth discussing in the following section, as well as, they produced insights of general applicability.

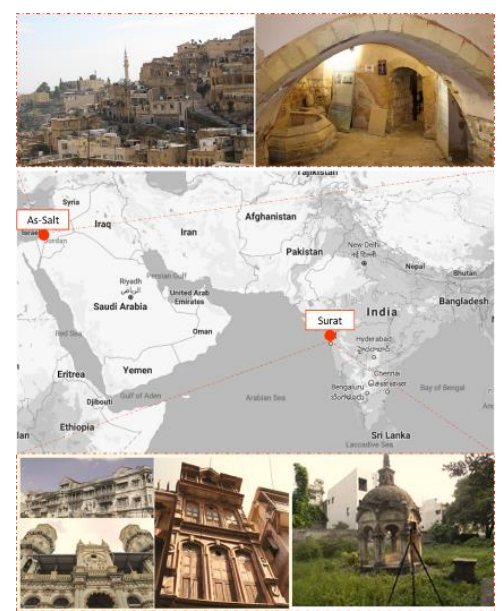

Fig. 1. Location and Built Heritage of the City of Surat, India and the City of As Salt, Jordan

\section{Towards smart urban heritage planning: insights from two research projects}

Section 4 is articulated in 3 sub-sections, the first 2 sections illustrate the 2 research projects (section 4.1 and 4.2), and section 4.3 discusses common issues and differences. It has to be highlighted that the 2 research projects started at one-year distance, therefore while the first case project started in 2018 and is now concluded, the second case project started in 2019 and is still ongoing. There is unbalance in terms of findings, which are still preliminary for the second case. As anticipated in the methodological section, it is not the goal of this discussion to attempt a comparative analysis of the two cases, nevertheless, some mechanisms are recurrent and it should also be noticed that all the tips and recommendation elaborated for the digitization of heritage, look perfectly pertinent to the two cases studies, located in Asia and the Middle East. Finally, the lessons learned from both cases reflect general issues arising from the implementation of digital technologies on planning heritage conservation, thus, they can be of interest for the wider international audience. 


\subsection{IT Indian Heritage Platform: Enhancing cultural resilience in India by applying digital technologies to the Indian tangible and intangible heritage}

The "IT Indian Heritage Platform: Enhancing cultural resilience in India by applying digital technologies to the Indian tangible and intangible heritage" is a bi-national and two years project funded by the UK Arts and Humanities Research Council (AHRC) UK and Indian Council of Historical Research (ICHR) New Delhi. It aims at exploiting the potential of digital technologies in raising awareness on the extraordinary cultural value of the tangible and intangible Indian heritage, currently under threat because of a variety of challenges, including rapid urbanization and demographic changes associated with the flow of new population moving from different areas of the country. The case study for this project is the city of Surat in Gujarat, a major metropolitan area experiencing dramatic migration flows. The research team has produced a sample of 10 exemplar heritage buildings, which will be made available to the wider public. It will be possible for the website users to navigate the buildings through 3D models, including information on constructive techniques and state of conservation. The data on the buildings will be complemented with further information reflecting intangible values connected to the tangible heritage. Although the website and associated dataset is the main outcome of this research, partner institutions from India and UK will continue working jointly beyond the project through a Center of Excellence. This will be internet based and will offer support to all those authorities, willing to implement the same approach (gtr.ukri.org). This project has been recently concluded and was conducted by an interdisciplinary team including experts on different fields, including engineering, architectural heritage conservation and planning. Key stakeholders in this project include the Archaeological Survey of India (ASI) and the city of Surat, with which the team has been engaging since the beginning of this project, by producing in 2018 recommendations for the city planners on how to implement the "Regulations for Heritage Buildings, Sites and Precincts in Surat". Following a stakeholder engagement workshop held in Surat in September 2018, the selection of the tangible heritage to digitalize has privileged paradigmatic examples of heritage buildings, expression of the unique identity of Surat. The process of acquisition of the formal authorization for capturing data in the chosen heritage areas has been extremely time consuming and has involved different levels (local, national and state authorities). It is paramount that researchers are aware about the difficulties and constraints in getting permissions to acquire the data, since they may have a significant impact on the project delivery. Following the data capture, the exploration of these heritage assets through digital technologies has been conducted by applying different techniques, with the aim to identify the most pertinent and achievable within the specific context of Surat. Isolated assets such as the Clock Tower or specific buildings within the wider archaeological areas of the Dutch and British cemeteries (Figures 2) have been either laser scanned or captured through photogrammetry. Larger areas or heritage sites, such as the complex archaeological sites of the Dutch and British cemeteries and the breath-taking Khammavati Step well have been either laser scanner or captured through aerial photos taken by UAV (Unmanned Aerial Vehicle) technology (drones). 

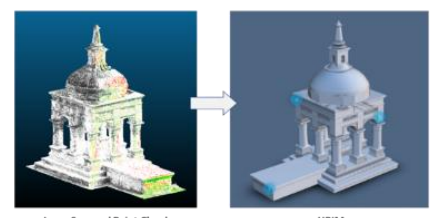

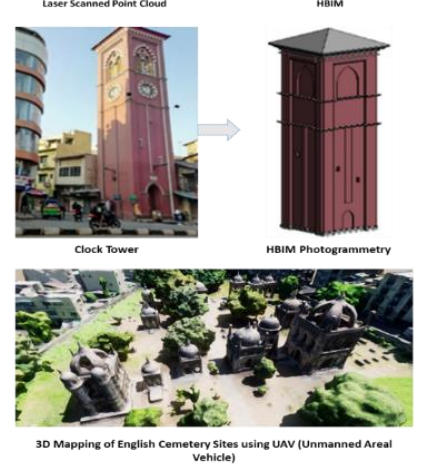

Fig. 2. Digitization of heritage

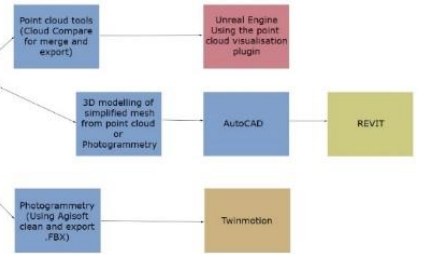

Fig. 3. Workflow

The digitalization conducted within this project has allowed to offer to both the authorities in charge of heritage conservation and to the wider public a variety of exemplar buildings, which will be made available through the Centre of Excellence, under construction, although challenged by issues of ownership and financial sustainability. Further considerations emerged from the application of different technologies allowed to confirm that: (1) Point clouds (raw data) from laser scanning technologies are the preferable option for the purpose of heritage documentation, although it is crucial to budget for sufficient data storage and to make sure that public authorities retain ownership on the raw data; (2) HBIM objects allow pulling together a variety of data, including costs, environmental performance, etc. and are therefore ideal to complement smart planning instruments and tools as well as smart heritage management plans for heritage cities, however, they require a simplification of the original point cloud and therefore should never be considered a replacement for raw data for the purpose of documentation; (3) For the purpose of tourist promotion and marketing, photogrammetry and aero photogrammetry remain the most viable options in financial terms, and lead to satisfactory outputs, however, they should not be considered a suitable replacement of raw data captured through laser scanning for the purpose of heritage documentation.

\subsection{IT and Conservation of traditional architecture and heritage in Jordan}

The "IT and conservation of traditional architecture and heritage in Jordan" is a binational and 2 year project funded by the UK Royal Academy of Engineering. It aims at developing a set of virtual models (3D models and BIM objects) suitable to support the construction sector and traditional architecture and heritage in Jordan. By developing a new set of BIM (Building Information Modelling) objects related to the traditional 
architecture heritage in Jordan, engineers and architects will be supported in the development of interventions on the historic city. 3D models will also be used to promote Jordanian heritage through virtual tours. The team initially focused on the City of As Salt. As-Salt is a historic city in Jordan, located $28 \mathrm{~km}$ west of Amman and approximately $50 \mathrm{~km}$ north-east of Jerusalem and $240 \mathrm{~km}$ south of Damascus, situated within the region of Al-Balqa, between the Jordan Valley and the Eastern Desert. The city of As-Salt is considered a unique city in Jordan, and probably in the whole region (Trillo et al., 2020; Ministry of Tourism and Antiquities \& Bank, 2005; ASCOP, 2016; Khirfan, 2013; Khuraisat, 2015; Khureisat \& Farid, 2015; Tarif, 2015). The built characteristics of the city such as the use of golden stone for the houses and its geographical location and social landscape differentiate the city from other Jordanian cities. As-Salt is one of the most consolidated and oldest urban settlements in Jordan and today the old city centre maintains a very local original character. However, the city's heritage is threatened by lack of maintenance, neglect and encroachment and the traditional built heritage of the Ottoman period is not protected by an appropriate legal framework.

The project approach is based on co-creation and is end-users centred. As such, the project implementation started with a Stakeholders' engagement and co-creation workshop hosted in Amman on 20th February 2020 by the Jordan Tourist Board. Researchers and experts worked collaboratively to identify challenges and opportunities for the application of Digital Technologies on Heritage Conservation in Jordan. The workshop also helped to refocus the mission for the Center of Excellence (COE), with an emphasis on documentation and knowledge sharing of international best practices on UAH conservation and a call for more clarity on the role that such a COE may play in the actual UAH Jordanian governance system. Two virtual local and international workshops were held in November 2020. The international stakeholder workshop was held to gauge suggestions and feedback on the Project from international experts, discuss transferability of international best practice with Jordan local stakeholders, and Knowledge transfer across international experts and local stakeholders. Over 100 participants from both workshops participated from government, industry, private sector and academia. The project has so far produced the point cloud and related virtual tour for a chosen exemplar house in the historic precinct of As Salt, the Qaqeesh house, with in the process to acquire data on a second exemplar building, Al-Jaghbeer house. HBIM objects are being derived from the raw data, or manually produced by resting on fieldwork with the aim to create a library of objects useful to be used by local architects and engineers. Figure 4 illustrates the characteristic features of Qaqeesh house based on laser scanned images and the development of a BIM object and a virtual tour. Through the use of digital technologies, the details of the unique features of the house can be interpreted. The walls of the house were built using local yellow stones and the cross vaults are the main roofing system with some barrel vaults. Wooden beams from tree trunks covered by reeds were used on a small area on the upper level. Further considerations emerged from the survey of Qaqeesh house and creation of BIM object process, which include: (1) Documentation of the house was necessary to start working on BIM objects. Many of the key documents related to As-Salt's built heritage were originally written in Arabic and therefore were translated for the purpose of this study. (2) Visualisations can be developed from 3D models such as the case with the laser scans for 
the Qaqeesh house which were further developed into a virtual 3D tour by the project's research partner. This 3D tour of the Qaqeesh house is made available on the Jordan Tourism website purposed to increase awareness of As-Salt's heritage and promote heritage tourism in Jordan.

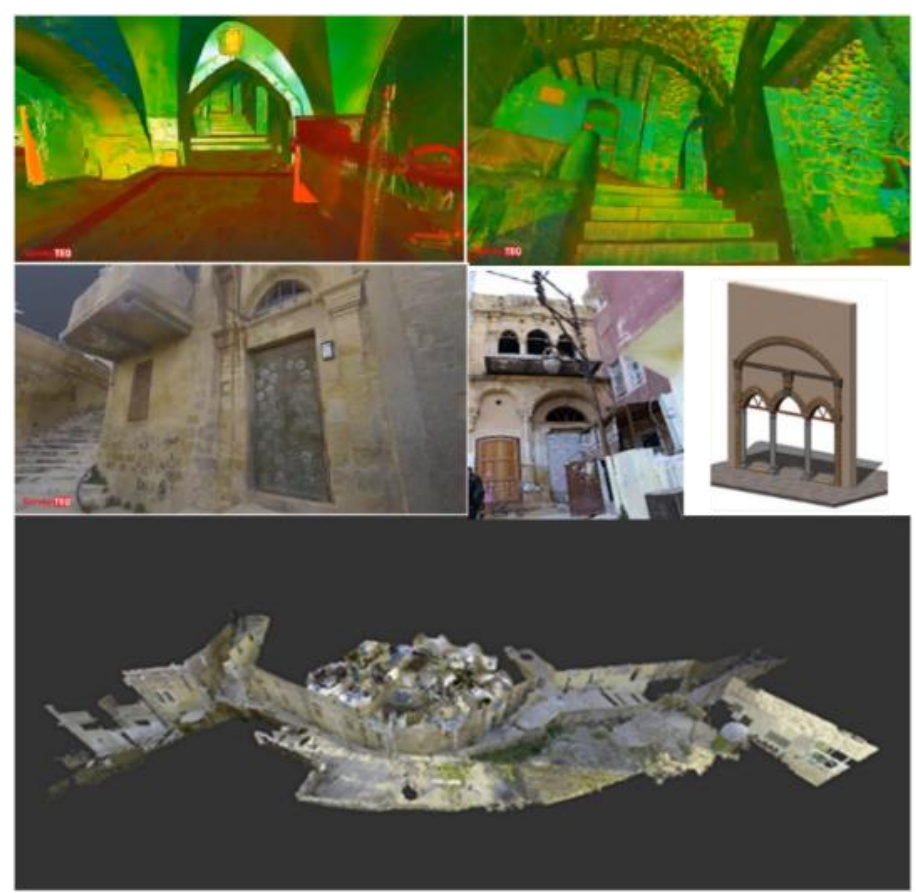

Fig. 4. Qaqeesh house point cloud and photos

The BIM process includes on several steps to get the full benefit from BIM technology, importing data manually remains essential to include extra data which can support architects and engineers. For example, materials characteristics is one requirement of using BOQ (Bill Of Quality) and BOM (Bill Of Materials), such data can be generated through specific studies and be added to the HBIM objects (Figure 5). While geometry can be derived from the point cloud, further data including thermal characteristic of the materials, resistance, can be generated and added manually, as well as, further data can include (Figure 6). 


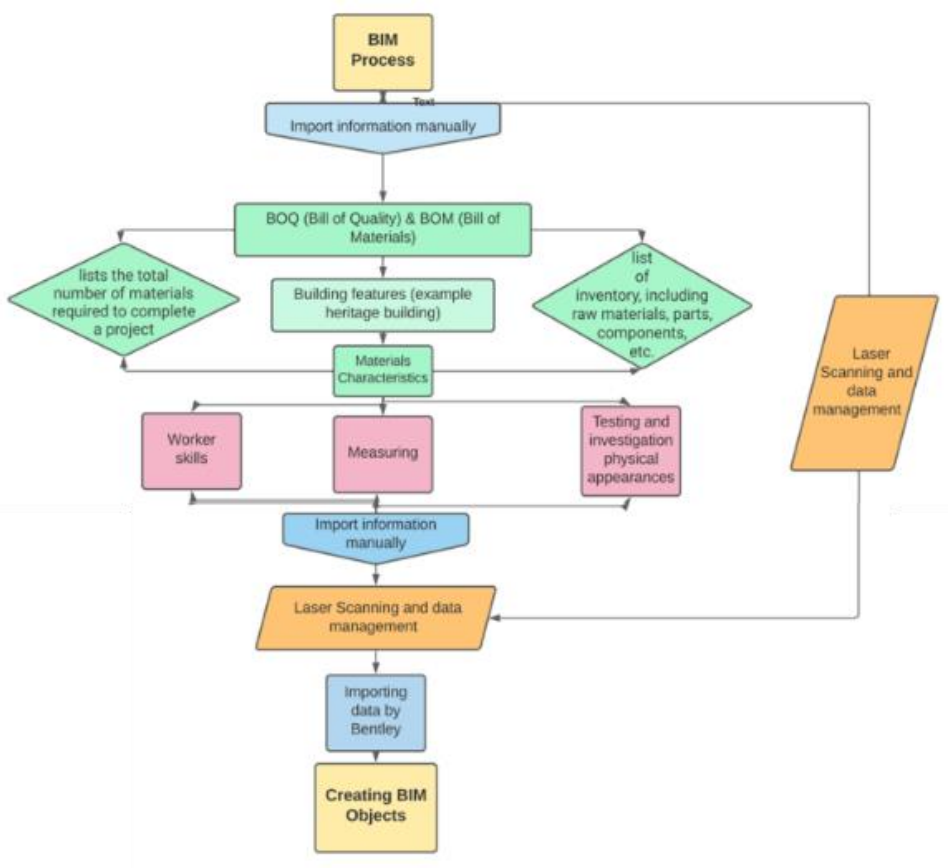

Fig. 5. Workflow process of BIM object creation

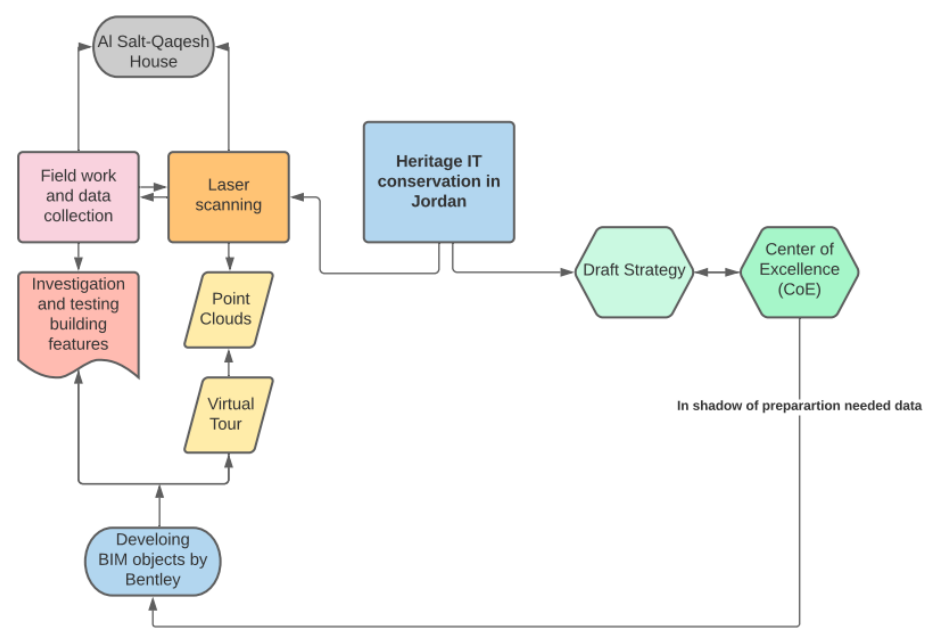

Fig. 6. Workflow process of Scan to BIM for Qaqeesh house 


\subsection{Lessons learned for smart-planning smart-heritage conservation.}

Both cases have confirmed a variety of issues that the literature and scholarship on heritage digitalization had clearly stated, such as:

(1) Digitalizing heritage assets request as first stage a data capture process, which should be carefully thought through the project delivery and specification. Time consuming process may be required in order to get permission from a variety of authorities, wherever the heritage is listed or protected. On the other hand, non-listed heritage often coincides with the wealth of historic buildings, which constitute the elements of the urban fabric, i.e. privately owned residential and mixed-use buildings. Issues in getting access to such heritage can be sometime insurmountable, and therefore the only option remains articulating the description of the building to the mere external shell.

(2) Different technologies present pros and cons, however, achieving the goal of acquiring high quality point clouds and storing raw data, remains essential for the purpose of heritage documentation and most importantly, in case any missing elements needs replacement due to natural or man-made disasters.

(3) Point 2 leads to two further points, issues in data storage and data exchange and issues in data ownership, which will be considered jointly because of their interconnected nature. The issue of the lack of awareness of local and national authorities in charge of heritage conservation seems acute in all the context investigated either through secondary data, or in the specific cases investigated through these projects, despite the fact that both case studies are included in context in which heritage is highly valued and properly protected. As matter of facts, the lack of systematic practices in creating structured public archives collating all data related to heritage mirrors the lack of awareness on the relevance of the issue. Heritage is a different object than standardized building elements and the necessity to store raw data to keep trace of the complexity and "imperfection" of historic buildings is paramount. This leads to difficulties in cross-collaboration as far as in the current performance of the web and hardware commonly used, but most importantly there is very little consideration of the necessity to create large storage spaces to be able to keep data in a systematic way. Finally, it is often unclear to the authorities in charge of managing heritage conservation that point clouds, i.e. raw data and not the final outcomes, are to be acquired to the public domain.

In addition to confirming aspects that the scholarship has flagged up, this study adds the planning and heritage management component to the discussion, with the following:

(4) For the purpose of planning heritage conservation, it would be extremely useful if architects and engineers could benefit from a systematic archive of HBIM object that, shadowing the rationale of the Handbooks for conservation, could offer guidance and support in deciding the best solutions. Those HBIM objects will present a simplified version of the original heritage elements, by readjusting the complexity of the geometry of the initial object through approximations, which are inevitable in the light of generating lighter 3D object, however, perfectly fit to the purpose of offering a living example rather than serving the aim to recreate them in case of destruction. Systematic archives of HBIM objects could feed into the management and conservation policies of 
heritage cities, in support to the work of engineers and architects and of the whole supply chain involved in the conservation process. In fact, HBIM can incorporate extra layers of information, usable in the construction industry, and suitable to enrich and make stronger any policy guidance and recommendation. The opportunity for architects and engineers to have available HBIM objects related to some exemplar buildings, would be un-valuable, since information retrieved for the exemplar buildings such as energy performance or structural resistance could be easily transposed thanks to the parametric nature of the BIM objects.

(5)Point 4 leads to another key aspect which makes HBIM models relevant to the planning process in heritage cities, i.e. the issue of transferring skills. In fact, HBIM include layers of information that go under the skin of the building and offer an opportunity to learn about the constructional techniques, which are the backbone of the materiality of the city. By circulating HBIM objects across the wider public of designers, architects, decision makers, builders, the culture and materiality of the heritage buildings could be preserved and transferred.

\section{Conclusion}

This paper was aimed at discussing the intersection between smart cities and smart heritage, with the aspiration to produce recommendations for planners, architects, local authorities and heritage conservation authorities. This goal has been achieved by discussing the findings of two research programmes, in the perspective of their applicability to the conservation planning process. In fact, it is through planning policies and plans that conservation is extended to the wider urban fabric, and this is an aspect that tends to be overlooked by both the scholarship and non-academic documents on heritage conservation because it is situated in a grey area between two distinct fields of specialism, i.e. heritage conservation on the one hand, planning on the other hand. As a result, while smart heritage and smart cities have been thoroughly scrutinized, and the correlation between digital technologies and planning and digital technologies and heritage widely investigated, the role of digital technologies on planning heritage conservation hasn't been covered.

Indeed, heritage is a very different object from other component of the urban fabric, this is because, the majority of heritage assets were produced before the system of industrial production of the built environment became pervasive. For this reason, concepts such as standardization of the architectural components or industrialization of the building elements are not applicable, and this tends to become a limitation in the application of technologies, that benefit from clustering information through similarities. On the one hand, heritage is not a standardized object and its beauty lies on "imperfections". On the other hand, a thoroughly precise representation of heritage is not necessarily functional to support planning instruments such as guidelines and regulations, while it can be un-valuable in case of post-disaster reconstruction.

It is therefore suggested that raw data based on high quality point clouds are always kept in the public ownership, to make sure that in case of forced reconstructions of missing elements or of the entire building, still it is possible to retrieve an accurate 
description of the physical details. Obviously, such data would require large amount of virtual infrastructure (data storage) and would result in limited opportunity for data sharing, and it is paramount that national and local authorities understand the importance of archiving properly all the raw data and to keep them in the public domain.

For what concerns the use of digital technologies for heritage representation, functional to support planning guidance and regulations, there is no need for such a detailed level of information regarding the physical details, while there might be the opportunity to upload layers of data, enriching the information attached to the architectural component such as availability, energy performance, etc. More agile files other than raw point cloud dataset may present a simplified version of the architectural component (e.g. revit files) and incorporate extra layers of information relevant to architects and planners. By making these components available in 3D objects open access libraries, the work of professionals will be hugely facilitated.

\section{References}

1. ANCSA (1960) Carta di Gubbio, Gubbio Charter, http://www.ancsa.org/in-sviluppo/wpcontent/uploads/2020/01/Carta-di-Gubbio-1960.pdf

2. Badawi,F., Nayer, A.: Jeddah City as A Contemporary Gateway: New Vision for City Smart Growth Management. Procedia Environmental Sciences, (37) 330-341, 2017. https://doi.org/10.1016/j.proenv.2017.03.063.

3. Barth,B.: Smart Cities or Surveillance Cities?, Planning Magazine, American Planning Association., (2019), Accessed on 1 December 2020: https://www.planning.org/planning/2019/mar/smartcities/

4. Borda, A and Bowen, J.: Smart Cities and Cultural Heritage - A Review of Developments and Future Opportunities. Bowen, JP, Diprose, G and Lambert, N (ed.) Electronic Visualisation and the Arts (EVA 2017). London, UK, 11 - 13 Jul 2017 BCS. (2017).

5. Coletta, C., Evans, L., Heaphy, L., \& Kitchin, R. (Eds.).: Creating Smart Cities (1st ed.). Routledge. (2018). https://doi.org/10.4324/9781351182409

6. Dornelles, A., Boyd, E., Nunes, R., Asquith, M., Boonstra, W., Delabre, I., . . Oliver, T. Towards a bridging concept for undesirable resilience in social-ecological systems. Global Sustainability, 3, E20. (2020). doi:10.1017/sus.2020.15

7. Dutra, LF; Porto, R.: Smart alternatives for the preservation of cultural heritage in the context of smart cities. Ibero-American Journal of Information Science , 13(1) (2020) 372-390, DOI: 10.26512 / rici.v13.n1.2020.26210

8. European Commission.: Smart Cities, (2021) Accessed on 1 January 2021 https://ec.europa.eu/info/eu-regional-and-urban-development/topics/cities-and-urban-development/city-initiatives/smart-cities_en

9. European Commission.: Expert Group on Digital Cultural Heritage and Europeana (DCHE), European Commission (2021), Accessed on 1 February 2021: https://ec.europa.eu/digitalsingle-market/en/expert-group-digital-cultural-heritage-and-europeana-dche

10. Facca, A., \& Aldrich, J. :Putting the Past to Work for the Future. The Public Historian, 33(3), (2011). 38-57. doi:10.1525/tph.2011.33.3.38

11. Ghadei M.: Amaravati - A City Reborn, Journey Towards a World-Class Smart City. In: Calautit J., Rodrigues F., Chaudhry H., Altan H. (eds) Towards Sustainable Cities in Asia and the Middle East. GeoMEast 2017. Sustainable Civil Infrastructures. Springer, Cham. (2018) https://doi.org/10.1007/978-3-319-61645-2_2 
12. ICOMOS (1987) Charter for the Conservation Of Historic Towns and Urban Areas (Washington Charter 1987), https://5129c385-3847-464f-90f146e3571d8ee3.filesusr.com/ugd/57365b_012ee3b47bea4183b8a7d344d1bcd340.pdf

13. Jawaid, M.F, Sharma, M., Pipralia, S, Kumar, A,: City profile: Jaipur, Cities, .:(68) (2017) https://doi.org/10.1016/j.cities.2017.05.006.

14. Ji, X., Shao, L.:The Application of Landscape Infrastructure Approaches in the Planning of Heritage Corridor Supporting System, Procedia Engineering, (198),1123-1127 (2017) https://doi.org/10.1016/j.proeng.2017.07.154.

15. Joss, S. , Cook, M. and Dayot, Y.: Smart cities: towards a new citizenship regime? A discourse analysis of the British smart city standard. Journal of Urban Technology, 24(4), pp. 29-49. . (2017) (doi: 10.1080/10630732.2017.1336027)

16. Karvonen, A., Cugurullo, F., and Caprotti, F., (eds). 2019. Inside Smart Cities: Place, Politics and Urban Innovation. London: Routledge.

17. Kitchin R. Big Data, new epistemologies and paradigm shifts. Big Data \& Society. April 2014. doi:10.1177/2053951714528481

18. Koukopoulos, Z., Koukopoulos, D., and Jung, J.J. 275 - 287 (2018) 'Real-time Crowd Management for Cultural Heritage Events: A Case Study on Carnival Parades'

19. Liu, C.: "Smart Solution for Protecting Cultural Heritage in China," 2018 3rd International Conference on Smart City and Systems Engineering (ICSCSE), Xiamen, China, 2018, pp. 788-791, doi: 10.1109/ICSCSE.2018.00170.

20. Mansuri, L, Udeaja, C, Trillo, C, Kwasi, G, Patel, D, Jha, K, Makore, C B and Gupta, S,: Scientometric Analysis and Mapping of Digital Technologies Used in Cultural Heritage Field In: Gorse, C and Neilson, C J (Eds) Proceedings of the 35th Annual ARCOM Conference, 2-4 September 2019, Leeds, UK, Association of Researchers in Construction Management, 255-264 (2019)

21. Mansuri, L. E., and Patel, D. A.:Artificial Intelligence-based Automatic Visual Inspection System for Built Heritage" Smart and Sustainable Built Environment, (2021). DOI: 10.1108/SASBE-09-2020-0139

22. Mar, A., Monteiro, F., Pereira, P., \& Martins, J.: An Application to Improve Smart Heritage City Experience. In Advances in Digital Cultural Heritage - International Workshop, Revised Selected Papers (Vl. 10754 LNCS, pp. 89-103). (Lecture Notes in Computer Science (including subseries Lecture Notes in Artificial Intelligence and Lecture Notes in Bioinformatics); Vol. 10754 LNCS). (2018) Springer Verlag. https://doi.org/10.1007/978-3-31975789-6_7

23. Mc Cann P., Ortega-Argiles R., Smart Specialisation, Regional Growth and Applications to EU Cohesion Policy, in Regional Studies 49(8), Pages 1291-1302 (2011)

24. Navarro De Pablos, F.J., Mosquera Pérez, C. y Cubero Hernández, A.: Ancient Cartographies as a Basis for Geolocation Models in Public Space: The Case of Giambattista Nolli and its Heritage Application. IOP Conference Series: Materials Science and Engineering, 471, 1-9. (2019)

25. Petti L, Trillo C, Makore BCN.: Towards a Shared Understanding of the Concept of Heritage in the European Context. Heritage:. 2(3) 2531-2544 (2019) https://doi.org/10.3390/heritage2030155

26. Petti L, Trillo C, Makore BN.: Cultural Heritage and Sustainable Development Targets: A Possible Harmonisation? Insights from the European Perspective. Sustainability. 12(3):926. (2020) https://doi.org/10.3390/su12030926 
27. Pica, V.; Cecili, A.; Annicchiarico, S.; Volkova, E. The Historical Small Smart City Protocol (HISMACITY): Toward an Intelligent Tool Using Geo Big Data for the Sustainable Management of Minor Historical Assets. Data, 4, 30. (2019) https://doi.org/10.3390/data4010030

28. Riganti, P.: Smart cities and heritage conservation: developing a smartheritage agenda for sustainable inclusive communities. International Journal of Architectural Research: Archnet-IJAR, 11, 16-27. (2017).

29. Sabri et al (2014) IOP Conf. Ser.: Earth Environ. Sci. 18012176

30. Scorza, F; Pilogallo, A; Casas, G.: Investigating Tourism Attractiveness in Inland Areas: Ecosystem Services, Open Data and Smart Specializations, in New Metropolitan Perspectives (2019)

31. Sun, Y., Song, H., Jara, A., and Bie, R.,: Internet of Things and Big Data Analytics for Smart and Connected Communities, in IEEE Access, (4) 766-773 (2016)doi: 10.1109/ACCESS.2016.2529723.

32. RTPI.: Smart City Regions, (2021) accessed on 1 February 2021: https://www.rtpi.org.uk/policy-and-research/programmes/better-planning/smart-city-regions/

33. Toha,M.,Ismail, H,: A Heritage Tourism and Tourist Flow Pattern: A Perspective on Traditional versus Modern Technologies, International Journal of Built Environment and Sustainability, 2(2), 85 - 92 (2015), https://doi.org/10.11113/ijbes.v2.n2.61

34. Trillo C., Aburamadan R., Udeaja C., Moustaka A., Baffour K.G., Makore B.C.N. (2020) Enhancing Heritage and Traditional Architecture Conservation Through Digital Technologies. Developing a Digital Conservation Handbook for As-Salt, Jordan. In: Bevilacqua C., Calabrò F., Della Spina L. (eds) New Metropolitan Perspectives. NMP 2020. Smart Innovation, Systems and Technologies, vol 177. Springer, Cham. https://doi.org/10.1007/978-3030-52869-0_18

35. Udeaja C, Trillo C, Awuah KGB, Makore BCN, Patel DA, Mansuri LE, Jha KN. 12(6):2172 (2020) Urban Heritage Conservation and Rapid Urbanization: Insights from Surat, India. Sustainability.;. https://doi.org/10.3390/su12062172 